\title{
Application of Cost Effective Solutions for Improving Voltage Sag Immunity of an Automated Cement Manufacturing Plant
}

\begin{abstract}
A.C.S. Wijayatilake
Abstract: Quality of the power supply becomes a key issue in factory automation. Especially voltage sags appearing on the electricity supply cause voltage sensitive equipment to shutdown and incurr heavy financial losses by interrupting the manufacturing process. However, effects of voltage sags can be minimized considerably if both the utility and the factory are working with good cooperation. This paper presents a Sri Lankan experience of finding out sag minimization or mitigation techniques through a study jointly carried out by the power supply utility and a customer.

By analyzing the plant disturbance reordered for a five a year period and measurements taken with a sophisticated power quality disturbance recorder it has been observed that voltage sags appearing on the factory supply are mainly caused by faults and subsequent switching operations taking place on the transmission and distribution network of the power utility. In addition to that switching operations carried out in the factory owned distribution network also result in voltage sags. In this study, investigations were carried out for estimating the severity of voltage sags associated with different types of faults in the utility network and their effect on the equipment installed in the factory. Especially the effects of voltage sags on the equipment vulnerable for production process like large induction motors and vector controlled Variable Speed Drives (VSD) were investigated to find out the possibilities for improving their voltage sag immunity. Simulations are extensively used to describe field observations. Adequate theoretical descriptions are given to justify field observations and simulation results.

Even though well proven sophisticated equipment is available for voltage sag mitigation these are not taken into consideration here due to their high cost. Instead, simple solutions such as distribution network rearrangement, reviewing protection settings and activating already embedded control algorithms in sensitive equipment are considered. Most of the solutions discussed here do not incur additional cost. Remarkablygood results have been gained by applying these techniques.
\end{abstract}

Key words: Voltage Sag, Variable Speed Drives, Induction Motors, System faults, Fault level

\section{Introduction}

Puttalam Cement factory is the largest cement manufacturing plant in Sri Lanka. It's daily cement production is approximately 32,000 tons. The factory is operating 24 hours a day and 7 days for a week. All machinery for cement production and processing plant in the factory are automated to improve productivity. This factory is situated on Puttalam-Palaviaya road, $3 \mathrm{~km}$ away from Puttalam Grid substation which steps down $132 \mathrm{kV}$ voltage in to $33 \mathrm{kV}$. Electrical demand of the cement plant is $15 \mathrm{MW}$ and is supplied by two separate $33 \mathrm{kV}$ overhead lines $3 \mathrm{~km}$ long. Both lines are running along two different rights of ways from Puttalam grid substation. Puttalam Grid substation has a single bus bar configuration. It consists of two $31.5 \mathrm{MVA}, 132 / 33 \mathrm{kV}$ transformers and six $33 \mathrm{kV}$ distribution feeder bays. The layout of grid substation, the feeding arrangement of the factory and the distribution network inside the factory are shown in Fig.1.

Fig.1 shows that the factory input voltage is $33 \mathrm{kV}$. There are four $4 \mathrm{MVA}, 33 / 3.3 \mathrm{kV}$ step down transformers installed in the factory. Some large motors and drives are directly fed from $3.3 \mathrm{kV}$ busbar. The general switching arrangement is also indicated in Fig.l by indicating the on/off status of each high voltage breaker in the network. Two $33 \mathrm{kV}$ incoming lines to the factory are started one from each side of the $33 \mathrm{kV}$ bus coupler of the Grid Substation and normally both lines are utilized to feedthe factory. As a practice the $33 \mathrm{kV}$ bus coupler, " $\mathrm{X}$ " as shown in Fig.1., at the factory is kept opened. Hence, two $33 \mathrm{kV}$

Eng. A.C.S. Wijayatilake,

Bsc Eng., C.Eng., MJE (SriLankn), 
busbars are operating as two independent sources. Equipment connected on both sides of the busbar is identical. There are several motors and drive systems used in the factory and the most important items for this analysis shown in Fig.1.

The factory has been the complaining to Ceylon Electricity Board (CEB) about frequent interruptions caused to the manufacturing process by shutting the down of the plant supply due to the operation of factory end $33 \mathrm{kV}$ breaker or tripping of large motors or drive systems. The reason was not clear and was believed to been have caused by transient voltage sags of the factory input power supply. Preliminary investigations revealed that factory supply interruptions were due to the opening of circuit breakers at the factory end of the $33 \mathrm{kV}$ feeders while the circuit breakers at the grid end were remained of healthy. The majority of tripping has been initiated by activating the under voltage (UV) relay installed at the supply input panel board of the factory. In certain instances some motors or drive systems which are vulnerable to the production process shutdown while the distribution system inside and outside the factory premises remained healthy. However, exact reasons for factory supply failures were not clear and believed to have been caused by voltage sags. Sudden power failures cause severe material wastage. The time taken to re-start the production process after sudden supply failure is considerably high and both of these factors result in high financial loss to the factory. Hence improving the quality and the reliability of factory power supply is not utmost importance for the factory management who has made several complaints to CEB to look into this matter. At their request CEB started analyzing this problem and the outcome of the analysis is described in the following sections.

\section{Study approach}

Both CEB and the electrical maintenance department of the factory have been jointly monitoring the quality of the electricity supply from year 2002 to date. Facilities incorporated in the factory automation system were used to monitor the voltage level, duration and exact time of occurrence of factory supply failure events. These incidents were matched with the events mentioned in the Disturbance Record Register kept at the grid substation in order to identify any relationship between plant failures and CEB network disturbances. The Disturbance Record Register at the grid is used to record all switching actions and operations of the distribution and transmission network components connected to the grid. CEB has been continuously carrying out this monitoring process for five years since 2003.

According to the results of the preliminary analysis it has been observed that some failures were caused by the faults on the distribution system and that a few were related to the faults and switching actions of the transmission network component directly connected to the feeding grid. However, the reason for the few instances are unknown and believed to be due to the faults on the distribution network inside the factory or fault or switching of the transmission network taking place at a point far away from the grid.

The monitoring process has justified that fault clearing procedure of distribution and transmission network of Puttalamgrid substation has a direct involvement in either activating UV relay at the factory supply injection point or making unstable some of the drives operating in the factory. Since the factory automation system is not sensitive enough to record transient variation of supply parameters such as voltages and currents accurately it was decided to install a sensitive disturbance recorder to store supply parameterfluctuationsduringdisturbances.

A more sensitive disturbance recorder has been installed at the factory supply injection point. The disturbance recorder was installed on 02/10/2003 and removed on 30/10/2003. The Disturbance recorder has identified twenty two of voltage sag related instances during a period of twenty eight days. The recordings confirm that the reason for the majority of sudden plant failures is due to voltage sags on one or more phases of the input supply. When the recorded events were matched with the network operator's Disturbance Record Register it has been found that $59 \%$ of voltage sags events were due to the faults on the distribution feeders of Puttalam grid other than the feeders dedicated to the cement plant. $27 \%$ of voltage sags corresponded to the fault clearing process of the incoming $132 \mathrm{kV}$ lines to Puttalam grid substation. $14 \%$ of the events were due to unknown reasons and may have been caused by faults inside the factory distribution network or starting of large motors. These findings are illustrated graphically in Fig.2. 
Fig. 3 shows a severe voltage sag event recorded in a disturbance analyzer. It corresponded to a single phase fault on one of the distribution feeders other than the feeders supplying to the cement factory. As shown in the figure, the network fault caused 50\% voltage drop in one phase lasting for a period of $0.5 \mathrm{~s}$. At that instance, the UV relay installed at the factory distribution network operated and disconnected the incoming utility supply disturbing the manufacturing process.

Most of the time the breaker at the incoming supply panel of the factory operates due to UV relay activation and shuts down the total plant. Sometimes the over current protection relays of the VSDs operated and disconnected them disturbing the manufacturing process.

A continuous voltage sag monitoring and recording system has been started in 2003 jointly by the utility and the factory. The monitoring process is still continuing. In this monitoring system utility records timing and other details related to faults and switching activities taking place in the utility network and factory records timing of UV operations and the list of motors and drives affected. By analyzing the information collected for the last five year period it is possible to make the following conclusions.

(i) Faults on the utility distribution as well as transmission network and subsequent fault clearing procedure create voltage dips at the factory supply.

(ii) Voltage dips are also created by some switching activities inside the factory such as motor stating, capacitor switching etc.

(iii) Electrical machine's behavior under voltage sags depend on their operating load. It has been noticed that the same drive disconnected for shallower sag with a shorter duration at a certain instance had come through a deeper sag with a longer duration at another instance.

Hence further analysis was carried out to investigate the measures which could be taken by the utility as well as by the factory to minimize the effect of voltage sags. The objective of the study was to identify costeffective solutions instead of introducing technically advanced high cost solutions such as Dynamic Voltage Regulator (DVR), Static Var Compensator (SVC) etc.

\section{Voltage sensitive equipment identification}

Through system monitoring and disturbance recording it has beenidentified that the following equipment is the most sensitive equipment for voltage sags. Disconnections of any of these drives jeopardize the total production process.

\section{(a) Waste gas fan drive}

This is a vector controlled variable speed (VSD) drive system with an induction motor (IM) rated at $600 \mathrm{~kW}$ with $380-480 \mathrm{~V}$ supply voltage. There is a separate $\mathrm{D} / \mathrm{Y} 5,3.3 / 0.725 \mathrm{kV}, 560 \mathrm{kVA}$ transformer to supply the converter.

\section{(b) Bag house fan drive}

This is a vector controlled (VSD) IM drive system of rated power $400 \mathrm{~kW}$ with $380-480 \mathrm{~V}$ supply voltage. Converter is fed by $3.3 / 0.725 \mathrm{kV}$ transformer.

\section{(c) Cement mill drive}

This is a $3.3 \mathrm{kV}, 1120 \mathrm{~kW}$ slip ring type IM motor. These drives and other large motors of the plant are shown in the single line diagram depicted in Fig.1 with their equipment ratings and motor types. All these motors and drives are incorporated with over current protection devices individually to isolate them under faulty or overload situations. Apart from that an UV relay is incorporated at the incoming supply panel to disconnect the supply in case the voltage sag is more than $30 \%$ of the nominal voltage and sag duration is more than $0.5 \mathrm{~s}$.

\section{Sensitive equipment behavior under voltage sags}

It is worthwhile to study the behavior of the equipment sensitive to voltage sags in order to understand the possible ride through techniques. Simulations are carried out to describe the behavior of direct connected IMs and vector controlled IM based VSDs at voltage sag situations. The software "MATLAB" is used for this purpose.

\subsection{Behavior of the directly connected IM motor under voltage sags}

Fig.4 shows the torque vs slip characteristics of a directly connected medium size IM motor. Similar motors are frequently found in the factory and used to drive pumps, blowers and cement mills. 
For any voltage drop the motor speed reduces and slip increases [1]. The amount of speed drop is proportional to the deepness of the voltage sag.

The pullout torque of $1 \mathrm{M}$ is directly proportional to the square of the stator supply voltage. As shown in Curve (a) of Fig.4, the pullout torque at 1 puvoltage is 1.8 pu of the rated torque. However, curve (b) shows that the pullout torque reduces to 0.9 pu of the rated torque when the supply voltage experiences a $30 \%$ voltage drop. As shown in two curves the pullout torque drops down by a considerable amount when the supply voltage is reduced. Due to supply voltage drop the operating point shifts from the point " $\mathrm{X}$ " on the curve (a) and can not settle on the stable region of the curve (b). Since motor electrical pullout torque is lower than the mechanical torque the motor stalls and UV relay settings should be adjusted to disconnect the motor before voltage is reaching to this level.

For applications such as pumps and blowers the torque is proportional to the square of the speed. At similar applications, depending on the inertia of the rotating parts the operating point may shift even on to the stable region of the lower pullout torque curve just by reducing the speed and preserving the stability. For instance, point " $Y$ " on curve (a) shifts to point " $Z$ " on curve (c) as shown in Fig.4 due to a 30\% drop in incoming supply. At this instance motor preserves the stability. However, as shown in curve (a) of Fig.4 the same motor can not maintain stability for a constant torque load of 1 pu due to the shifting of the operating point " $\mathrm{X}$ " on to the unstable region due to the $30 \%$ drop in supply voltage.

Hence stability of IM to voltage sag depends on the size of the voltage reduction, duration of the sag and the characteristics of the load torque applied on it.

Fig. 5 shows the behavior of the IM motor rated $1120 \mathrm{~kW}$ used to run cement raw mill when there is a line to line fault on a public supply feeder of the utility distribution network that causes voltage dips on all three phases of $3.3 \mathrm{kV}$ bus bar of the plant. As shown in Fig.5 a large current is drawn during the period of voltage sag when electrical torque is constant. The higher the sag level the larger the absorbing current is. Hence, the time of withstanding that current will be depending on the thermal overloading capability of the motor windings. Generally an over current relay is used to disconnect the motor at similar instances. As shown in Fig.5, severe torque fluctuations and a slight increase in percentage slip can be noticed.
If the motor is very critical for the process the disconnected motor canbe reconnected if voltage restores before it comes to a standstill. However, precautions should be taken to improve the mechanical strength of motor shaft and coupling equipment since re-connection drastically increases the transient torque applied on the rotor [1].

Immediately after the sag is cleared, busbar voltage further reduces and resumes slowly due to high motor inrush currents flowing during the acceleration period. Since a large number of motors are operating in the factory the possible voltage drop due to simultaneous acceleration of the motors should be taken into account when UV relaysettingsarecalculated.

Henceit canbeconcluded that an induction motor can withstand voltage sags up to a certain time margin. Process destruction an due to voltage sags can be minimized by individually setting a protectiondeviceforeachmotorratherthanhaving a common UV relay at the incoming supply. However, a detailed study on the operating torque, the level of importance of the motor for the factory process is required tofind out theoptimum setting.

\subsection{Behavior of VSDs under voltage sags}

Unlike directly connected induction motors, in a VSD the electricity network and the motor are connected through a power electronic link. As a consequence, the motor back emfsupport against the busbar voltage reduction is not available in drives. Precious protection devices are incorporated in VSDs to safeguard power electronic converter against abnormal operating conditions. Hence VSDs are more sensitive for voltage sags than directly connected motors.

The DC link voltage of the converter depends on the type of the voltage sag experienced. Three phase voltage sag is the most critical and depending on the severity of the sag the diodes of the rectifier bridge stop conduction blocking energy supply to the DC link. When there is a voltage sag on one or two phases of the incoming supply, the healthy phases are continuously supplying energy to the DC link and the DC link voltage drop is not comparatively severe as in the case of the three phase sag situation. However, the current flow through the conducting diodes may be higher since the DC link voltage is lower than the rated value. To avoid possible damage on rectifier bridge diodes, overcurrent protection devices are employed to disconnect the drive from the mains at such instances [1]. 
Operation of Waste Gas Fan Drive when three is a line to line fault on the distribution system is simulated to study the behavior of VSD under voltage sags and results are presented in Fig.6. As shown in Fig.6, a line to line fault on the distribution network reduces voltages of two phases up to $30 \%$ and the fault clearing time is $100 \mathrm{~ms}$.

DC link voltage is the constraint for the performance of the drive system. If energy supply to DC link is stopped completely or partially the resulting DC link voltage is lower than the allowable limit. Then the DC link capacitor has to provide necessary energy to the motor. The ride through capability will be decided by the ability of the DC link capacitor to provide energy required to operate the motor and the driven load. As shown in Fig.6, the reduction in energy supplying to the DC link capacitor results in further decaying of the DC link voltage. At a certain DC link voltage the electromagnetic torque is not large enough to maintain the load torque and stability of the VSD is lost and motor velocity start reducing. A voltage sensor is incorporated in DC link to disconnect the converter if DC link voltage reduces normally below $10 \%$. Fig. 7 shows that during the period of network fault the healthy phase of the rectifier absorb abnormally high current to charge the DC link capacitor. Over current protection devices are incorporated in VSDs to disconnect the drive at such instances to safeguard diodes on the rectifier bridge.

If voltage resumes before DC link voltage drops to the allowable minimum level, the rectifier start conduction and the system returns to the normal state. However, a large inrush current is absorbed to re-charge the DC link capacitor as shown in Fig.7. Hence, it is not recommended to reconnect the disconnected VSD automatically when the power supply returns to normal level even though the motor is still rotating at a lower speed in order to avoid damage on power electronic equipment due to the severe high current flowing through them as a consequence of non synchronization of the inverter with the stator residual voltage of the motor.

Unlike mains connected motor, a careful study is necessary to implement a proper ride through technique for a VSD and sometimes the process has to tolerate the resulting deviations in speed.

\section{Measures implemented by the utility to minimize voltage sags}

As a responsible utility the following measures have been taken by CEB to minimize the voltage sags generating in the utility network and passing them on to the consumer. The objective of all these techniques is to minimize voltage sags and reduce sag magnitude as well as sag duration through cost effective means.

\subsection{Identification of the critical zone fornetwork faults}

The collected information with the Disturbance Analyzer confirms that the faults on the distribution and transmission network cause voltage sags at the factory supply voltage. According to the utility network breakdown information collected during the last five year period, three phase faults are very rare and majority of the faults are earth faults the involving single phase or two phases. Unlike faults on the distribution network faults on transmission lines supplying power to the Grid completely disturb the power flow to the load. Hence transmission faults are more severe. Depending on the star-delta connection of the transformers the single phase voltage sag on $132 \mathrm{kV}$ side may cause sags in two phases of the $33 \mathrm{kV}$ side.

The main reason for distribution line faults are tree touching, lightning, accidents, birds and salt contamination on overhead conductors. Lightning has been identified as the main reason for transmission network faults.

Since three phase faults are very rare in theutility network, single phase faults on the transmission lines feeding the grid and one or two phase faults on the distribution network are simulated to identify the critical zone. In identifying thecritical zone the present UV settings of the factory input (given under section 4) and the behavior of the IM and VSDs under voltage sags (discussed under section 5) are taken into account. Since the pullout torque of an IM become half when the input voltage drop is $30 \%$ it can be considered as the maximum allowable voltage drop and faults causing more than $30 \%$ voltage drop are critical for motors. Hence, faults occurring within the critical zone should cause more than $30 \%$ voltage drop at the factory supply. Results gained through simulating faults on different locations of the utility network are shown in Fig.8. As shown in the figure, faults occurring on distribution feeders within $30 \mathrm{~km}$ distance from 
the grid cause more than $30 \%$ voltage drop at the factory busbar. Therefore that zone is the critical distribution zone when voltage sags on factory supply are concerned. Similarly any fault on the transmission line connected to the grid causes more than $40 \%$ voltage drop at the factory supply and hence, the total length of the transmission line feeding the grid is considered as a critical zone.

Faults on the critical zone disturb the factory process. More attention is taken to minimize the faults occurring within the critical area. Frequent maintenance programs are arranged to rectify the defects on these lines. High priority is given for tree trimming because it is the main reason for phase to ground faults. Salt contamination on insulators due to sea breezing and subsequent insulator flashing over during early morning period causes single phase faults on coastal lines. Insulators are washed once in a three months period to avoid that problem and the suitability of polymer insulators against salt contamination is being investigated. Earth wires are well maintained to reduce lightning effects. Special attention will be given to tower footing resistance improvement to avoid back flashovers.

\subsection{Isolating the factory supply feeders}

The factory is fed by two $33 \mathrm{kV}$ lines of $3 \mathrm{~km}$ long, running along both sides of the main road. Faults occurring on these lines are very rare and it has been noted that the factory process is disturbed by the faults occurring on the public feeders connected to the same busbar. Up to 2005, the $33 \mathrm{kV}$ bus coupler "B" shown in Fig.1 was kept closed and in 2005 the decision was taken to keep the bus coupler opened to isolate factory supply from the long feeders running to coastal and rural areas which are prone to frequent breakdowns. As shown in Fig.9, opening $33 \mathrm{kV}$ bus coupler of the grid substation reduces the reflection of faults on public feeders on the factory supply voltage. Theoretically the effective impedance seen between fault location and the factory has been increased by opening the bus coupler. It is a very effective technique for reducing voltages dips passing to the factory due to faults occurring on other feeders.

\subsection{Improving feeder protection}

The voltage sag duration is depending on the time taken by the feeder protection device to isolate the faulty section. After rearranging feeders at the grid substation as described in (7.2), faults occurring on the critical zone of one public feeder connected to the factory supply busbar are important and the strategies applied to improve the fault clearing time of that feeder is considered here.

At present earth fault and over current relays are used to protect $33 \mathrm{kV}$ feeders. IEC 255 inverse time protection curves are used in relays. CT ratio is 400/5 and Plug Setting Multiplier and Time setting Multiplier was set at 0.1 and 0.15 respectively. The fault level of $33 \mathrm{kV}$ bus bar of the grid when the bus coupler is opened is $4.6 \mathrm{kA}$. (132kV fault level is $6.5 \mathrm{kA}$ ) If an earth fault takes place at the end of the critical zone about $30 \mathrm{~km}$ away from grid the fault current is $185 \mathrm{~A}$. The relay operating time for Standard Inverse (SI) curve is $0.67 \mathrm{~s}$ and if Extremely Inverse (EI) curve is employed it is around 0.58s. Thereby the earth fault clearance times for faults occurring within the critical zone can be improved significantly by changing operating curves. However with a single line to ground fault occurrat the feeder end about $50 \mathrm{~km}$ from the grid, the fault current is $159 \mathrm{~A}$. The relay operating time for (SI) curve is 0.75 and if (EI) curve is employed it is around 0.82 . If (EI) curve is selected the fault clearing time for the faults beyond the critical zone become slightly larger as shown in Fig10.

The relay curves shown in Fig.10 confirm that the fault clearance time can be reduced significantly for the faults happening within the critical zone by changing relay operating curve fromSI to EI. If breaker operating time of $60 \mathrm{~ms}$ and additional $40 \mathrm{~ms}$ delay time is assumed the time taken to clear the single line to ground fault on the critical zone has decreased from $0.7 \mathrm{~s}$ to $0.5 \mathrm{~s}$. The difference is a $30 \%$ increase and many motors and drives in the factory can ride through resulting voltage sag.

\section{4 increasing fault level of the transmission network}

By increasing the short circuit capacity of the transmission network, the source impedance of the feeding network can be reduced and it leads to the reduction in the depth of the voltage sags appearing at the factory supply.

In 2005, 100MW base load operating power plant has been connected to the $132 \mathrm{kV}$ bus bar of the grid substation and the associated interconnections in the transmission network increases $132 \mathrm{kV}$ fault level of Puttalam grid from $4.6 \mathrm{kA}$ to $6.5 \mathrm{kA}$. 


\section{Measures implemented by the factory to minimize voltage sags}

Since voltage dips disturb the production process the factory has to implement certain strategies to minimize the disturbances. Eventhough equipment of advance technology is available like UPS, DVR etc. they are not discussed here because of the higher cost. Instead, techniques applicable with minimum cost are discussed here.

\section{1 improving the fault level by network re-arrangement}

By increasing the short circuit capacity of the distribution network it is possible to reduce the depth of the voltage sag caused by the disturbances in the utility network or inside the factory distribution system. The immunity level to voltage dips increases with the increase of short circuit capacity because it reduces the source impedance of the feeding network.

One way of increasing the fault level of the factory distribution system is to increase the number of feeders supplying to the factory from the grid substation. At present the factory is fed by two $33 \mathrm{kV}$ circuits from the grid substation. However, at the factory each circuit is connected to separate $33 \mathrm{kV}$ busbars and operated as two separate loads as shown in Fig.1. According to this feeding arrangement each feeder supplies half of the factory demand. It is recommended to close plant's $33 \mathrm{~V}$ bus coupler " $\mathrm{C}$ ", shown in Fig.1, to make two feeders parallel. If a breaker is installed between points " $D$ " and " $E$ ", shown in Fig.l, parallel operation of all transformers inside the factory is possible. Thereby fault level of the $3.3 \mathrm{kV}$ busbar at the plant increases from 12kA to 19kA. (132/ $33 \mathrm{kV}, 31.5 \mathrm{kVA}$ transformer impedance is $10 \%$ and $33 / 3.3 \mathrm{kV}$, 4MVA t/f impedance is $7.7 \%$ ) Since equipment and switchgear installed inside the factory are designed for higher short circuit capacity it is not necessary to replace them

\subsection{Adjusting t/f tap settings to improve voltage}

Since $33 / 3.3 \mathrm{kV}$ transformers have tap changers to match the variations in supply voltage within the range 1.05 and 0.95 , the voltage of factory distribution network can be slightly increased by adjusting transformer taps. At the grid, the $33 \mathrm{kV}$ busbar voltage is fixed at 1pu level. Hence the depth of the voltage sags can be improved considerably by increasing $3.3 \mathrm{kV}$ busbar voltage by $5 \%$ with tap adjustment. Since electrical equipment is normally designed at least to tolerate
$+6 \%$ higher voltages this tap adjustment will not be harmful for equipment. As shown in Fig. 11 10\% voltage drop appearing in $3.3 \mathrm{kV}$ busbar before tap adjustment reduces to $5 \%$ after the tap is adjusted.

\subsection{Activating extra facilities embedded on drive control systems.}

At present VSD systems are designed with higher voltage dip immunity level than the past. The general setting of the UV relay in DC bus is $10 \%$ drop for $20 \mathrm{~ms}$ [1]. However modern VSDs incorporate embedded solutions such as kinetic energy recovery technique [2] and magnetizing energy recovery technique etc. which can be used for ride through operations for an extended time period but sacrificing the speed. These facilities are available at the critical VSDs within the factory but have to be activated and controllers should be re-tuned to match with the load connected. Kinetic energy recovery technique can be applicable even to older versions of VSDs provided that user has access for reprogramming the control systems. No additional equipment is necessary and only to add a subroutine to the speed control loop of the control algorithm.

For instance VSD used in Waste Gas Fan Drive is a vector controlled induction motor drive system and according to the manufacturer's hand book this VSD incorporates kinetic energy recovery system [2]. If this technique is activated, in case of a DC link voltage dropping more than the defined level, drive can be further operated by pumping the kinetic energy stored in the rotating masses to charge the DC link capacitors while speed is reducing. Thereby ride through period can be increased. Either drive system will come to standstill smoothly or accelerate back to the normal speed once the voltage is restored before speed reaches to zero. Since the operating speed reduction for a short duration does not affect on the process and rotating mass of the pumps releases kinetic energy necessary for DC capacitor charging better results can be achieved if these two techniques are activated.

Fig.12 shows that the DC link voltage remains constant since the kinetic energy of rotating mass is released on to the DC link during the voltage sag period. However as shown in Fig.12 speed reduces during this period but VSD accelerates to the desired level once the voltage resumes. As shown in Fig.13 currents flowing through the diode rectifier bridge is within the limit unlike the case shown in Fig.7. 
These techniques can be activated without incurring any cost but the gain setting or tuning of the PI controller needs good understanding about process speed requirement. Drive instability may result due to very large gain settings [2]. It is recommended to carry out simulations first to identify these limits.

\subsection{Utilization the local Generation}

The factory is planning to set up a generating station to sell electricity to the national network. Then it is recommended to provide an in feed to the factory as well. Connecting a local generator to the factory distribution network increases the short circuit capacity of the network and make the network less sensitive to disturbances. If all sensitive load can be taken to a separate busbar and a local generator is connected to that better results canbe obtained. However, a short-circuit study has to be carried out to ensure that the equipment in the factory can bear the increased shortcircuitcurrent.

\subsection{Reviewing under voltage protection settings}

One UV relay is mounted at the supply input panel of the factory and it is used to safeguard inside equipment from transient voltage sags of the incoming supply. Since single UV relay is installed at the plant supply input, it operates to disconnect the entire plant even for smaller voltage drops lasting very short durations. Therefore it is recommended to install UV relay for each sensitive equipment by considering the sag immunity level of that particular equipment. On the other hand by setting UV relays individually tolarge motors which are vulnerable to the production process with more flexible settings at the UV relay mounted on the plant feeding point avoid unnecessary total plant failures.

However, detailed simulations are required to study the ideal settings of each UV relay proposed to be installed at the sensitive equipment. For instance, the amount of voltage drop ride through characteristics of the IM motor used for Crusher Drive is illustrated in Fig.14. It clearly indicates that the motor can withstand $40 \%$ drop. If voltage drop exceed more than $40 \%$ the withstanding duration of the drop is less than $100 \mathrm{~ms}$. When voltage drop due to absorbing of high excitation current and the resulting further voltage drop on the other IMs available in the factory are concerned, $10 \%$ margin can be further added and the recommended under voltage setting for this motor is $30 \%$. In order to avoid thermal stresses on windings the allowable maximum sag duration is limited to $1.5 \mathrm{~s}$.
Since breakers areelectrically controllable they can be switched on if voltage returns before the motor comes to the standstill. However, the connecting equipment should be able to bear the high transient torque.

Hence results gained through a detailed simulation study on each and every motor in the system assists in identifying the most optimistic UV settings for each motor and based on that the central UV relay settings can be relaxed further to avoid unwanted total plant failures occurring due to certain voltage sags though the many equipment installed in the factory can ride through them.

\section{Results of the Analysis}

The graph depicted in Fig.15 shows the improvement achieved so far. When comparing with the situation in the years 2003 and 2004 a remarkable progress has been achieved. The measures discussed in sections (8.4) and (8.5) are at the analyzing stage by now. Successful implementation of them will bring outstanding improvement.

\section{Acknowledgement}

The author acknowledges the assistance given by Eng. Kamal Perera of CEB and Mr. K.M. Pathmanathan of Puttalam Cement Plant.

\section{References}

[1] E.R. Collins and A.Mansoor, "Effectsof momentary voltage dips on the operation of induction and synchronous motors", IEEE transactions on industry applications, Jul/Aug. 1990.

[2]E.M.Sisa, "Power outages and power dip ridethrough", IEEE industrial and commercial power systems technical conference, May 1995 


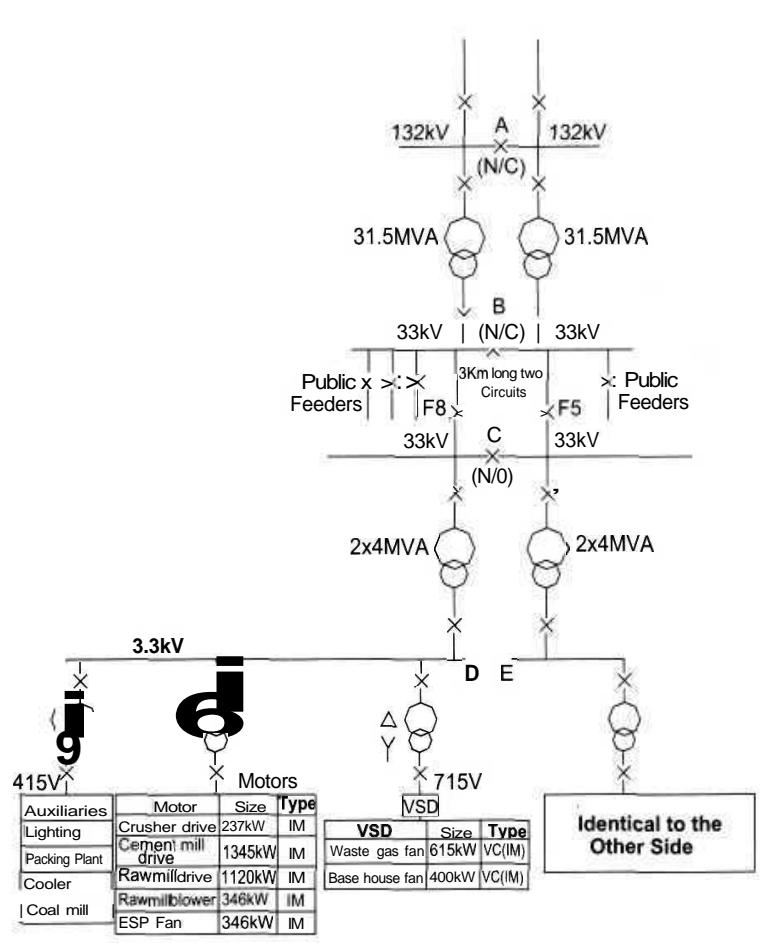

Fig.1: Part of the utility network, factory feeding arrangement and simple electrical layout inside the factory

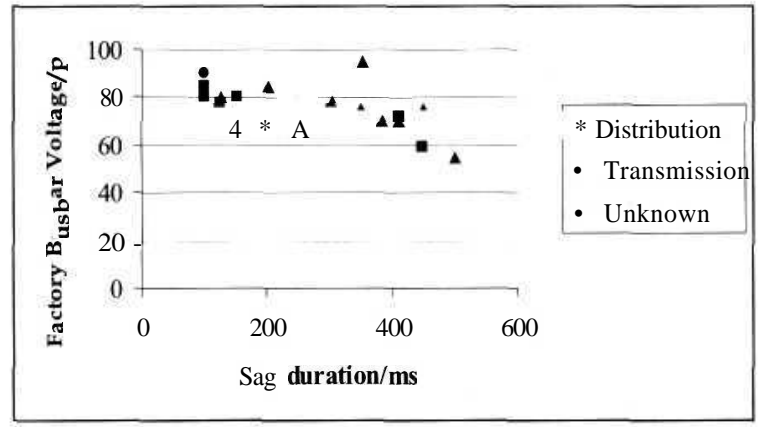

Fig2: Magnitude versus duration of transient voltage sags recorded with a disturbance analyzer

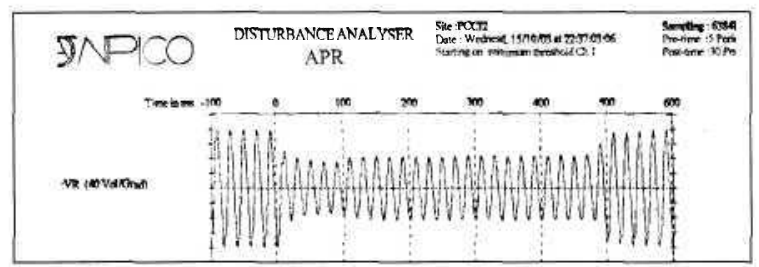

Fig3: Voltage sag event recorded using the Disturbance Analyzer

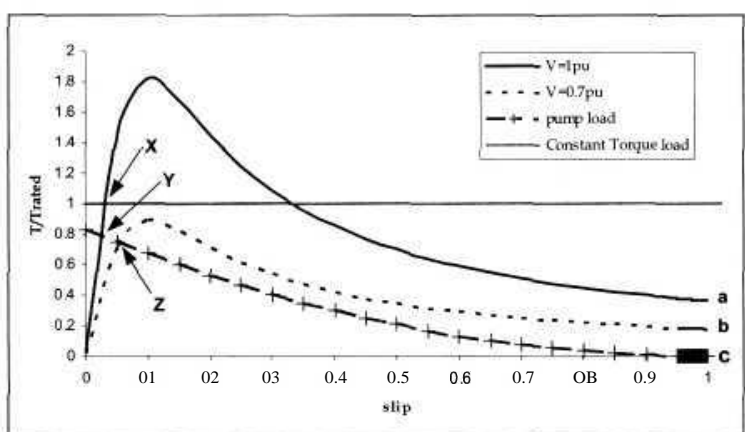

Fig4. Torque Vs Slip characteristic of an IM and different load characteristics
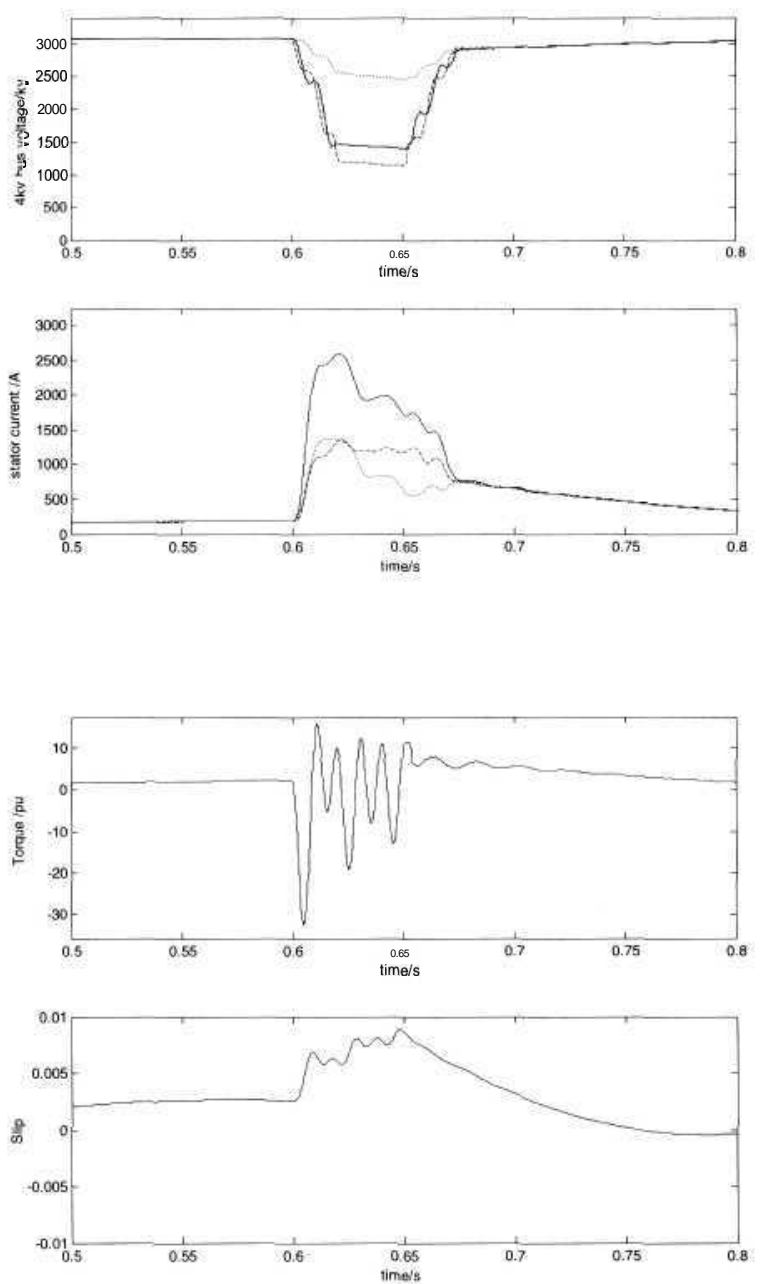

Fig.5 Behavior of IM when it is subjected to the voltage sag due to line to line faulton distribution network. (i) $3.3 \mathrm{kV}$ phase voltages (b) stator currents (c) Electrical torque (d) Percentage slip variation 

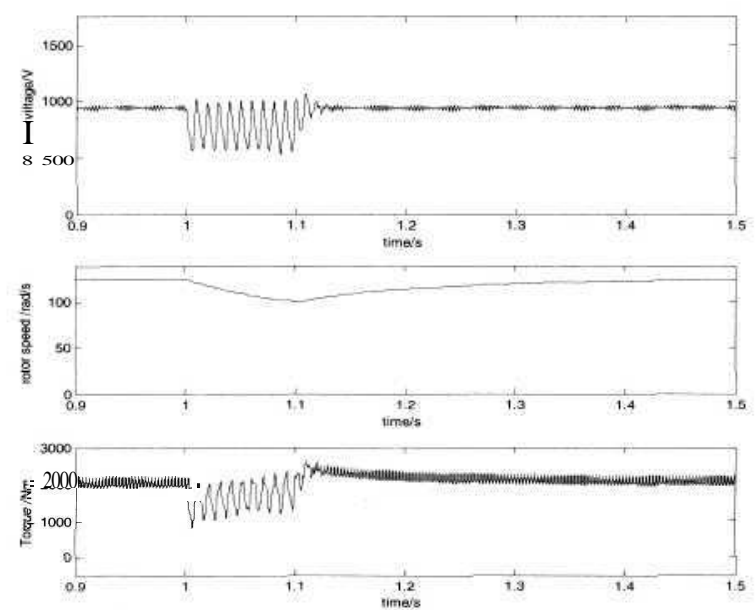

Fig.6 Behavior of VSD used in Waste Gas Fan when it is subjected to the voltage sag due to line to line fault on the distribution network. (i) DC link voltage (b) rotor speed (c) torque fluctuation
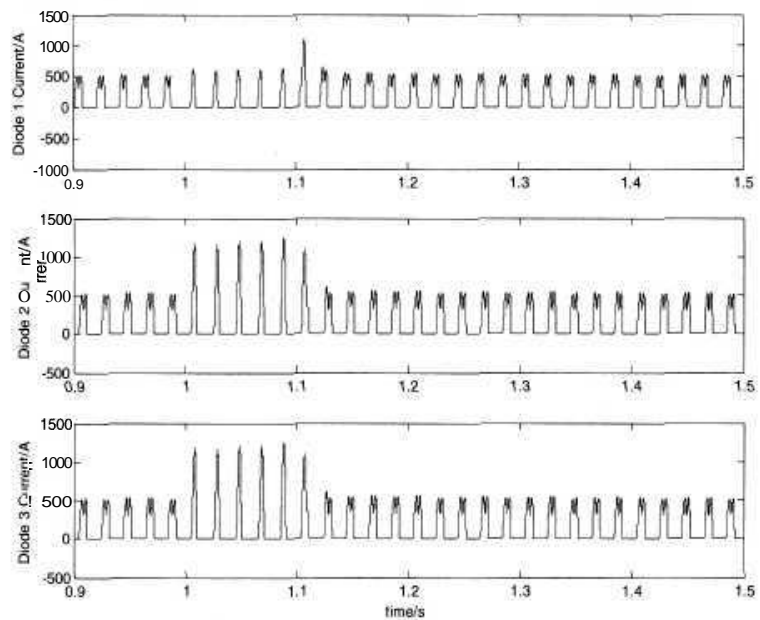

Fig. 7 Currents through the diodes of rectifier bridge of the VSD used in Waste Gas Fan for the same fault described in Fig.(6)

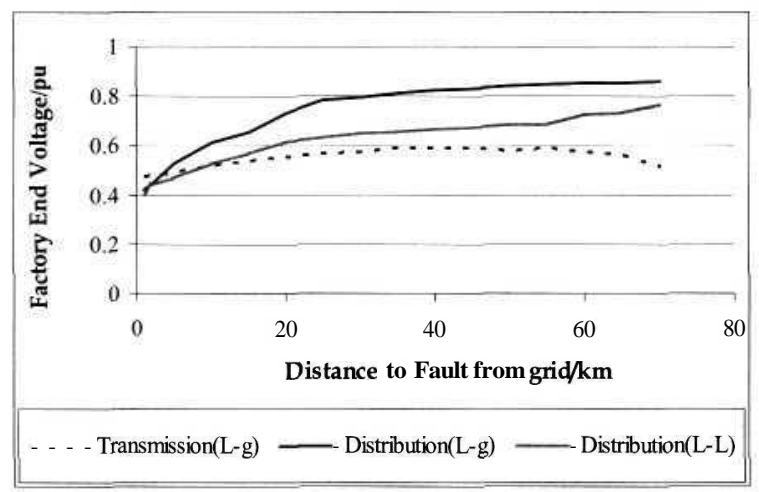

Fig.8 Distance from the grid substation to the fault Vs factory end voltage for different type of faults occurred in distribution and transmission network.

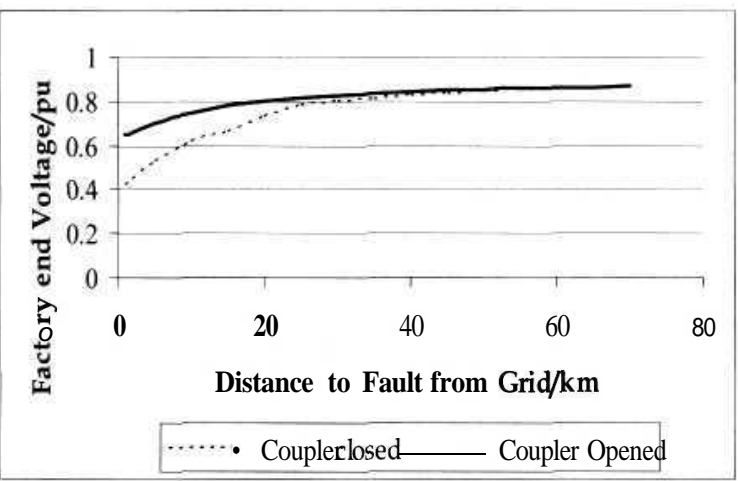

Fig.9 Distance from the grid substation to the fault Vs factory end voltage for line to line fault on the distribution network when $33 \mathrm{kV}$ bus coupler is kept opened or closed.

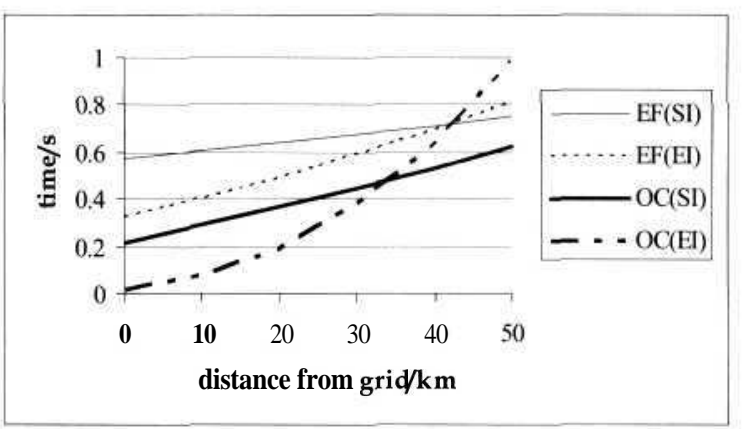

Fig.10. Distance vs relay operating time for over current and earth fault situations when SI or EI relay curves are employed.

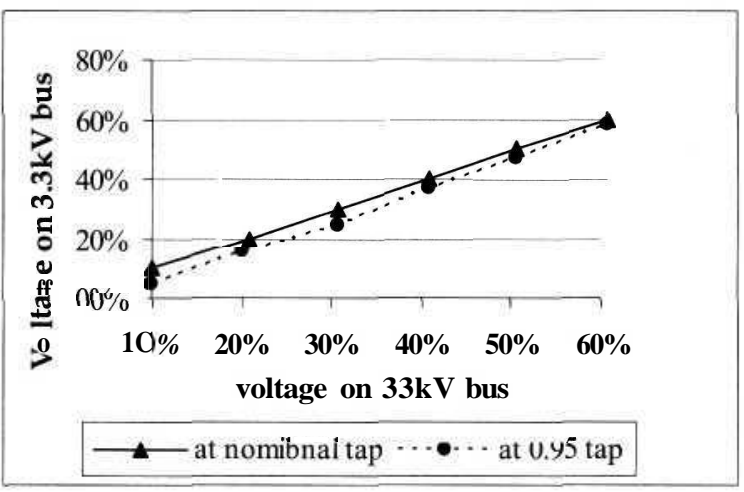

Fig.1l. Variation of $3.3 \mathrm{kV}$ bus voltage when taps on $33 \mathrm{kV}$ winding is adjusted. 

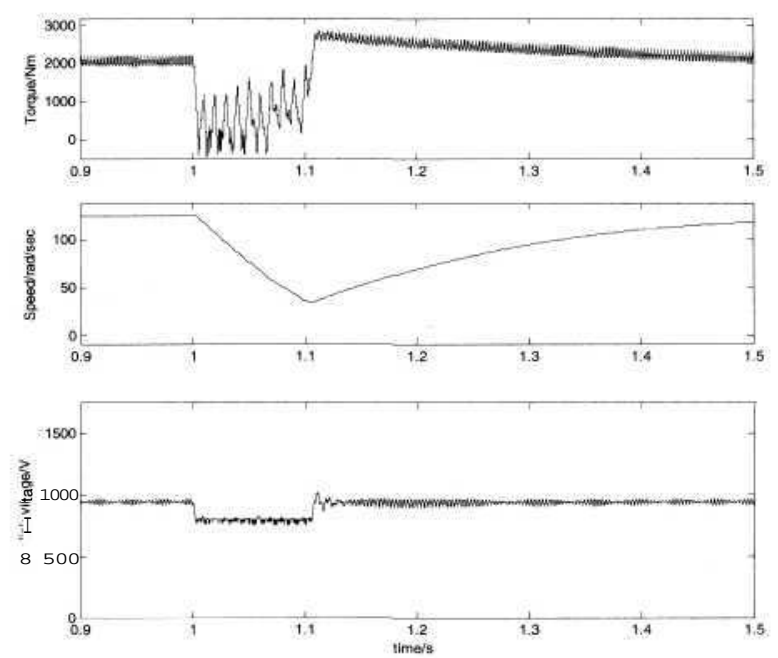

Fig. 12 Behavior of VSD used in Waste Gas Fan when Kinetic energy recovery function is activated during the voltage sag due to line to line fault on the distribution network. (i) rotor speed (ii) electrical torque(iii) DC link voltage
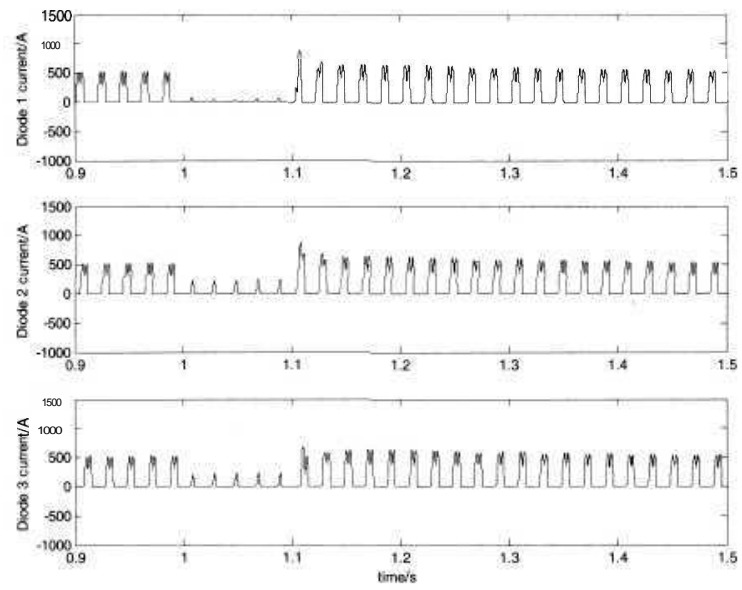

Fig.13 Currents through the diodes of Rectifier Bridge of the VSD for the same fault described in Fig. (12)

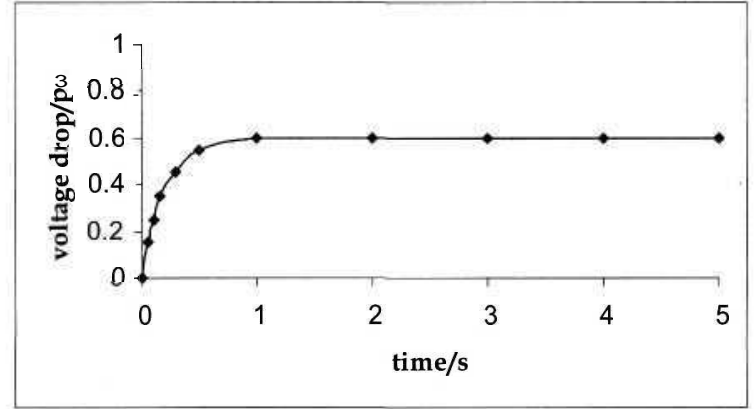

Fig. 14 Under voltage withstand characteristic of the Crusher Drive. $(237 \mathrm{~kW}, 3.3 \mathrm{kV}$, IM motor operates at rated torque)

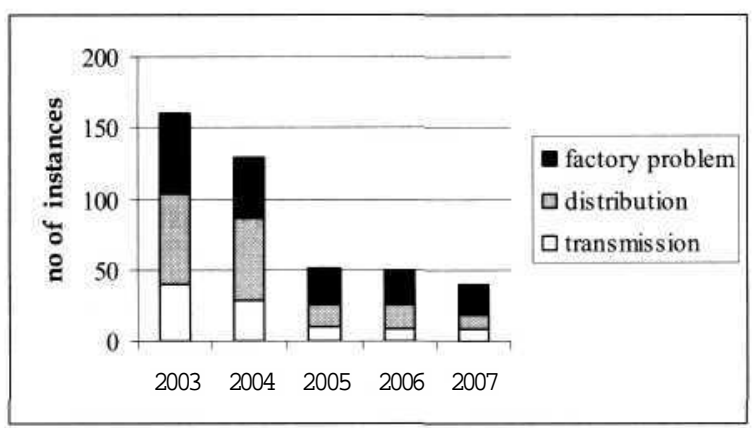

Fig.15. Identified reasons for the abnormal plant disconnection in each year and the validity of the counter measures employed to bring them down. 